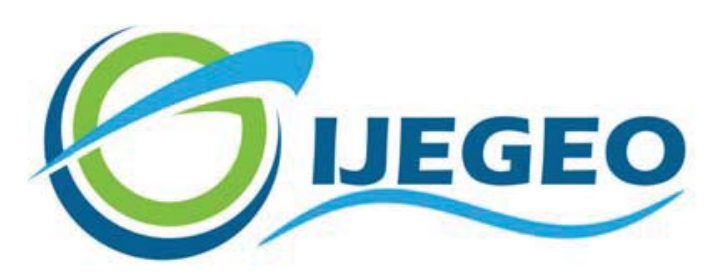

International Journal of Environment and Geoinformatics (IJEGEO) is an international, multidisciplinary, peer reviewed, open access journal.

\title{
Development of Modeler for Automated Mapping of Land Surface Temperature Using GIS and LANDSAT-8 Satellite Imagery
}

\section{Sachin SUTARIYA, Ankur HIRAPARA, Mukesh K. TIWARI}

\author{
Chief in Editor \\ Prof. Dr. Cem Gazioğlu \\ Co-Editors Prof. Dr. Dursun Zafer Şeker, Prof. Dr. Şinasi Kaya, \\ Prof. Dr. Ayşegül Tanık and Assist. Prof. Dr. Volkan Demir
}

Editorial Committee (June 2022)

Assoc. Prof. Dr. Abdullah Aksu (TR), Assoc. Prof. Dr. Uğur Algancı (TR), Assoc. Prof. Dr. Aslı Aslan (US), Prof. Dr. Levent Bat (TR), Prof. Dr. Paul Bates (UK), İrşad Bayırhan (TR), Prof. Dr. Bülent

Bayram (TR), Prof. Dr. Luis M. Botana (ES), Prof. Dr. Nuray Çağlar (TR), Prof. Dr. Sukanta Dash (IN), Dr. Soofia T. Elias (UK), Prof. Dr. A. Evren Erginal (TR), Assoc. Prof. Dr. Cüneyt Erenoğlu (TR), Dr. Dieter Fritsch (DE), Prof. Dr. Ç; Prof. Dr. Manik Kalubarme (IN), Dr. Hakan Kaya (TR), Assist. Prof. Dr. Serkan Kükrer (TR), Assoc. Prof. Dr. Maged Marghany (MY); Prof. Dr. Micheal Meadows (ZA), Prof. Dr. Nebiye Musaoğlu (TR), Prof. Dr. Masafumi Nakagawa (JP), Prof. Dr. Hasan Özdemir (TR), Prof. Dr. Chyssy Potsiou (GR), Prof. Dr. Erol Sarı (TR), Prof. Dr. Maria Paradiso (IT), Prof. Dr. Petros Patias (GR), Prof. Dr. Elif Sertel (TR), Prof. Dr. Nüket Sivri (TR), Prof. Dr. Füsun

Balık Şanlı (TR), Dr. Duygu Ülker (TR), Prof. Dr. Seyfettin Tsaş (TR), Assoc. Prof. Dr. Ömer Suat Taşkın (TR), Assist. Prof. Dr. Tuba Ünsal (TR), Assist. Prof. Dr. Sibel Zeki (TR) 
Short Communication

\title{
Development of Modeler for Automated Mapping of Land Surface Temperature Using GIS and LANDSAT-8 Satellite Imagery
}

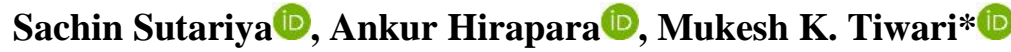

Department of Irrigation and Drainage Engineering, College of Agricultural Engineering and Technology, Anand Agricultural University, Godhra, Gujarat, INDIA

* Corresponding author: MK Tiwari

E-mail: tiwari.iitkgp@gmail.com

Received 04.11.2020

Accepted 16.10.2021

How to cite: Sutariya et al., (2022). Development of Modeler for Automated Mapping of Land Surface Temperature Using GIS and LANDSAT8 Satellite Imagery. International Journal of Environment and Geoinformatics (IJEGEO), 9(2):054-059, doi. 10.30897/ijegeo.820906

\begin{abstract}
Land surface temperature (LST) can be described as the temperature of the earth's surface and it is most important parameters in climate change, evapotranspiration, urban climate, vegetation monitoring and environmental studies. LST, calculated from remote sensing data, is used in many areas of science such as; hydrology, agriculture, forestry, oceanography etc. The main objective of this study was to develop a model making the LST retrieval process quite simple and automated. This model developed using the ArcGIS Desktop 10.3.1 with the Model Building. Without the model, the process of retrieving LST is very long, and it is susceptible to many mistakes. In this model when user inputs required bands (4,5 and 10) of Landsat- 8 data then the model calculate automatically LST and display output. The model first makes the conversions to top of atmosphere (TOA) spectral radiance. Then NDVI is calculated based on band 4 and 5 (NIR and RED) reflectance. Then using the TOA and NDVI model calculates brightness temperature (BT) and Proportion of Vegetation respectively. After that it calculate Land Surface Emissivity with the help of NDVI and Proportion of Vegetation and finally, the model calculates land surface temperatures in degrees Celsius. The findings highlight the capabilities of GIS modelers for such spatial estimation. The developed model can be helpful to field engineers and researchers for using Landsat-8 images for direct estimation of LST, to be used for different other studies to derive LST based products.
\end{abstract}

Keywords: : LANDSAT-8 data, Land surface temperature (LST), ArcGIS Desktop

\section{Introduction}

Land surface temperature (LST) is one of the most important parameters in climate change, evapotranspiration, and urban climate, vegetation monitoring and environmental studies. LST can be described as the temperature of the earth's surface. As well known, it is not easy to retrieve land surface temperature for large areas with the help of remote sensing (Guillevic et al., 2018; Çelik et al., 2019). In the land surface processes, LST is a key parameter, it not only acting as an indicator of environment change, but also due to its control of the upward terrestrial radiation, and subsequently, the control of the surface sensible and latent heat flux exchange with the atmosphere (Sun, 2008). Remote sensing is beneficial for understanding the spatiotemporal land cover- land use change in reference to the essential physical properties in terms of the surface radiance, intensity and emissivity data. LST, calculated from remote sensing data, is used in many areas of science such as; hydrology, agriculture, forestry, oceanography etc. For the determine the problem related with the environment obtaining surface temperatures and using them in different analysis is important (Orhan and Yakar, 2016; Kaya et al., 2015- 2017). Within the last few decades, many studies are administered on thermal analysis using MODIS, ASETR, Landsat TM/ETM and
Landsat 8 data (Ibrahim and Abu-mallouh, 2018). In this paper developed tool is effortless and does not require any background knowledge so scientists and even field engineers can use it very easily in their project work and for different researches. The model introduced in this paper has been developed using ArcGIS Desktop 10.3.1 with the Model Building tool available in the ArcGIS. Without the model, the process of retrieving LST is very long, cumbersome and error prone and it is susceptible to many mistakes. The model presented in this paper is used for calculating the LST of a given LANDSAT 8 image data with the input of the fourth (red wavelength), fifth (near infrared (NIR) wavelength), and tenth (thermal infrared sensor (TIRS) wavelength) bands.

\section{Materials and Methods Input Data}

Landsat 8 satellite imagery acquired on 23 - JAN-20 (path/row: 148/44) was used as input data in this study. The Landsat 8 is one of the Landsat series satellites of NASA (National Aeronautics and Space Administration). This satellite has 16 days repeat cycle period. At the website of USGS (United States Geological Survey) Earth Explorer Landsat-8 data is available free of cost. This instrument has two sensors: the operational land imager (OLI) and thermal infrared sensor (TIRS). OLI sensor has total 9 bands and each 
band with $30 \mathrm{~m}$ spatial resolution (except for panchromatic band- $15 \mathrm{~m}$ spatial resolution) and the TIR sensor has two thermal long wave infrared bands with $100 \mathrm{~m}$ spatial resolution as shown in Table 1 below (Department of the Interior U.S. Geological Survey, 2016).

\section{Study Area}

Panam canal command area was selected as the study area in this research work. It comes under the periphery of Panchmahal district, lies between latitud0e $22^{\circ} 27^{\prime}$ to $22^{\circ} 48^{\prime} \mathrm{N}$ and longitude $73^{\circ} 24^{\prime}$ to $73^{\circ} 32^{\prime} \mathrm{E}$. It contains two climatic regions; the northern part of the command comprises subtropical wet climate. It has a total length of canal about $99.73 \mathrm{~km}$ and area of about $2312 \mathrm{~km} 2$ (231200 ha). It has a Cultural Command Area of about 36405 ha. Landsat 8 satellite imagery acquired on $23-$ JAN-20 (path/row: 148/44) was downloaded from USGS website. Figure 1 below illustrates the location of the study area with Landsat 8 satellite imagery.

Table 1. The band characterizes of LANDSAT-8

\begin{tabular}{ccccc}
\hline Band & Resolution $(\mathbf{m})$ & Spectral Band & Wavelength $(\mu \mathbf{m})$ & $\begin{array}{c}\text { Solar irradiance } \\
\left(\mathbf{W} /\left(\mathbf{m}^{2} \boldsymbol{\mu m}\right)\right.\end{array}$ \\
\hline 1 & & & & 2031 \\
2 & 30 & Coastal/Aerosol & $0.433-0.453$ & 1925 \\
3 & 30 & Blue & $0.450-0.515$ & 1826 \\
4 & 30 & Green & $0.525-0.600$ & 1574 \\
5 & 30 & Red & $0.630-0.680$ & 955 \\
6 & 30 & NI & $0.845-0.885$ & 242 \\
7 & 30 & SWI & $1.560-1.660$ & 82.5 \\
8 & 30 & SWI & $2.100-2.300$ & 1739 \\
9 & 15 & Panchromatic & $0.500-0.680$ & 361 \\
10 & 30 & Cirrus & $1.360-1.390$ & - \\
\hline
\end{tabular}

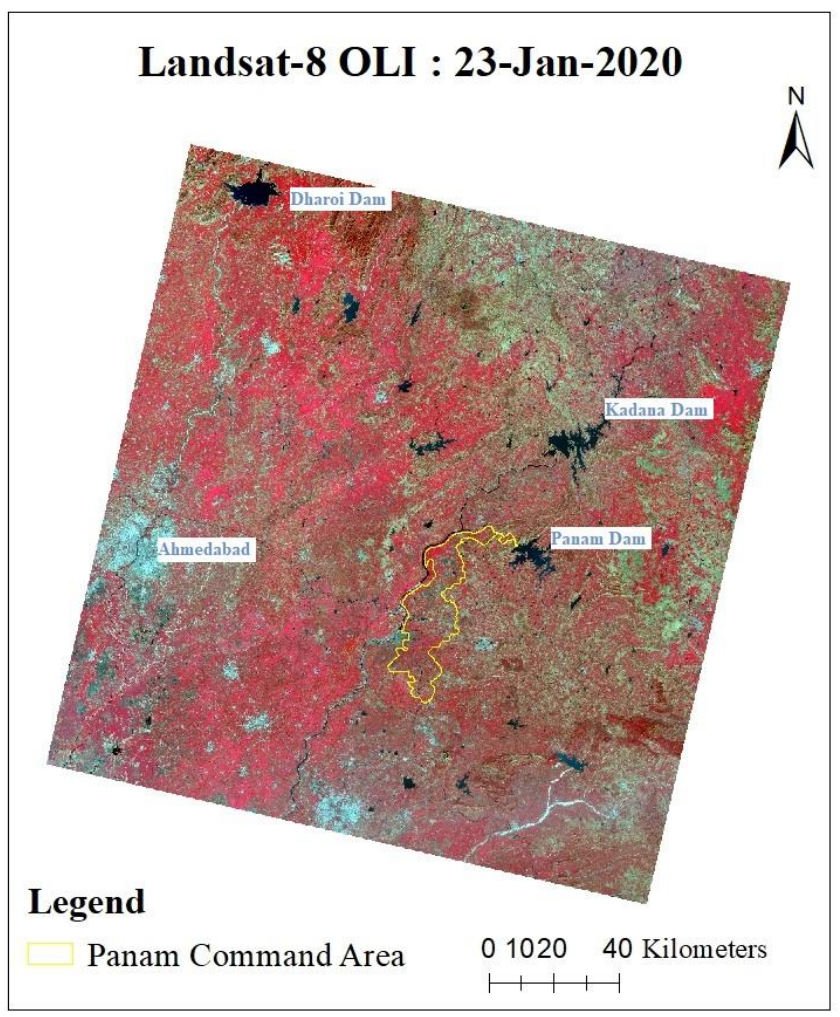

Fig. 1. Landsat-8 image covering study area with Panam command area boundary

\section{Methodology}

From the Landsat- 8 digital data; Red, NIR and TIRS bands were used for generate Model of LST and steps described by (Avdan and Jovanovska, 2016) (Oğuz,
2017; Zaharaddeen, et al., 2016; Jeevalakshmi,et al., 2017) were used to generate the model. The major steps are: 
i) Converting digital numbers (DN) to top-of-theatmosphere (TOA) radiance, ii) Conversion of radiance to at-sensor brightness temperature, iii) Calculation of Normalized Difference Vegetation Index (NDVI), iv) Computation of Proportion of Vegetation (PV), v) Estimating the surface emissivity using an empirical relationship based on the NDVI, and vi) Calculating LST using the simplified Plank's law.

\section{i) Top of atmospheric spectral radiance}

In the first step of LST estimation, band 10 from Landsat-8 OLI data has been used for estimation of top of atmospheric (TOA) spectral radiance (L $\lambda$ ):

$$
L \lambda=M_{I} \times Q_{\text {cal }}+A_{I}-Q_{i}
$$

Where, $L \lambda=$ Top of atmospheric spectral radiance, $\mathrm{M}_{\mathrm{l}}=$ Band-specific multiplicative rescaling factor, $\mathrm{Q}_{\mathrm{cal}}=$ Band 10 image, $A_{1}=$ and-specific additive rescaling factor, $\mathrm{Q}_{\mathrm{i}}=$ correction for Band 10 .

\section{ii) Conversion of Radiance to at Sensor Temperature}

Conversion of radiance to at-sensor temperature is carried out to estimate the brightness temperature using the thermal constants which are given in Landsat-8 metadata file:

$$
B T=\frac{K_{z}}{\ln \left(K_{1} / L \lambda\right)+1}-273.15 \quad \text { Eq. } 2
$$

Where, $\mathrm{BT}=$ Brightness temperature, $\mathrm{K}_{1}$ and $\mathrm{K}_{2}=\mathrm{Band}-$ specific thermal constants, $\mathrm{L} \lambda=\mathrm{Top}$ of atmospheric spectral radiance

\section{iii) Calculation of Normalized Difference Vegetation Index (NDVI) for Emissivity Correction}

The amount of vegetation present can be estimated using NDVI and it can also be used to infer general vegetation condition. The NDVI is required for computing the Proportion of Vegetation $\left(\mathrm{P}_{\mathrm{V}}\right)$ which is highly related with NDVI, and emissivity $(\varepsilon)$ should be calculated, which is related to the $\mathrm{P}_{\mathrm{V}}$ :

$$
N D V I=\frac{N I R(b a n d 5)-R(\text { band 4) }}{N I R(b a n d 5)+R(\text { band 4) }} \quad \text { Eq.3 }
$$

Where, NDVI=Normal Difference Vegetation Index, NIR = Near-infrared band $($ Band-5), $R=$ Red band (Band-4)

\section{iv) Computation of Proportion of Vegetation $\left(P_{V}\right)$}

$$
\boldsymbol{P}_{v}=\left(\frac{\mathrm{NDVI}-\mathrm{NDVI}_{s}}{\mathrm{NDVI} I_{v}-\mathrm{NDVI}_{s}}\right)^{2} \quad \mathrm{Eq} .4
$$

Where, $\mathrm{P}_{\mathrm{v}}=$ Proportion of Vegetation, NDVI=Normal Difference Vegetation Index, $\mathrm{NDVI}_{\mathrm{V}}=0.5, \mathrm{NDVI}_{\mathrm{S}}=0.2$. v) Estimating the surface emissivity (LSE) using an empirical relationship based on the NDVI

For calculating LSE in to the model when the NDVI value is less than 0 , it is classified as water, and the emissivity value 0.991 is considered. For NDVI values between 0 to 0.2 , it is classified that the land is covered with soil and there is no vegetation, and the emissivity value 0.996 is considered and the NDVI value is greater than 0.5 , it is classified to be covered with vegetation assigned, and the value of 0.973 is considered. In last values between 0.2 and 0.5 are classified mixtures of soil and vegetation covers the emissivity can be calculating following,

$$
\varepsilon_{\lambda}=\varepsilon_{v \lambda} P_{v}+\varepsilon_{s \lambda}\left(1-P_{v}\right)+C_{\lambda}
$$

Where, $\varepsilon_{\lambda}=$ Land Surface Emissivity, $\mathrm{P}_{\mathrm{v}}=$ Proportion of Vegetation, $\varepsilon_{\mathrm{v} \lambda}=0.973, \varepsilon_{\mathrm{s} \lambda}=0.996, \quad \mathrm{C}_{\lambda}=$ Surface roughness $(0.005)$

\section{vi) Land surface temperature Computation}

Land surface temperature (LST) is computed using the following equation:

$$
T_{s}=\frac{B T}{\left(1+\left[\frac{x B T}{p}\right] \ln \varepsilon_{\lambda}\right]} \quad \text { Eq.6 }
$$

Where, $\mathrm{T}_{\mathrm{s}}=$ land surface temperature $\left({ }^{\circ} \mathrm{C}\right), \mathrm{BT}=\mathrm{Brightness}$ temperature, $\varepsilon_{\lambda}=$ Land Surface Emissivity, $\lambda=$ limiting wave length (10.895), $\rho=1.438 \times 10^{-2} \mathrm{~m}$. To accomplish the above estimation, an algorithm was developed in ArcGIS 10.3.1. For estimation of LST for any other Landsat -8 image for any other date, the same algorithm can be executed. The different steps involved in development of the algorithm are presented in Figure 2.

\section{Results and Discussion}

The developed algorithm using the ArcGIS was applied for the estimation of LST from Landsat-8 imagery automatically as the modeler shown in Figure $3 \& 4$. For the demonstration purpose Landsat- 8 satellite imagery acquired on 23-JAN-2020 (path/row: 148/44) was used in this study. Only three bands of study area (band 4, band 5, and band 10) are required to run model successfully. The final LST map of Landsat 8 imagery is calculated automatically as shown in Figure 5 after inputting required bands four, five and ten into the model. $26.08{ }^{\circ} \mathrm{C}$ and $16.42{ }^{\circ} \mathrm{C}$ were found to be the highest and lowest temperatures in the scene, respectively. For one of the stations where the maximum and minimum temperature were collected as $29^{\circ} \mathrm{C}$ and $14{ }^{\circ} \mathrm{C}$, the LST using the modeler was obtained as 19.16 ${ }^{\circ} \mathrm{C}$, that can be to the minimum temperature obtained for the day. 


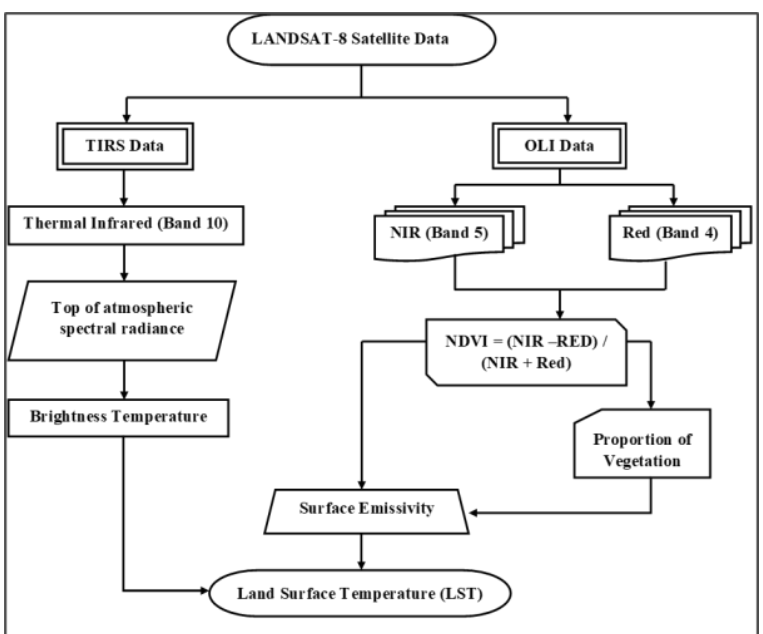

Fig. 2. Flow chart of LST retrieval model

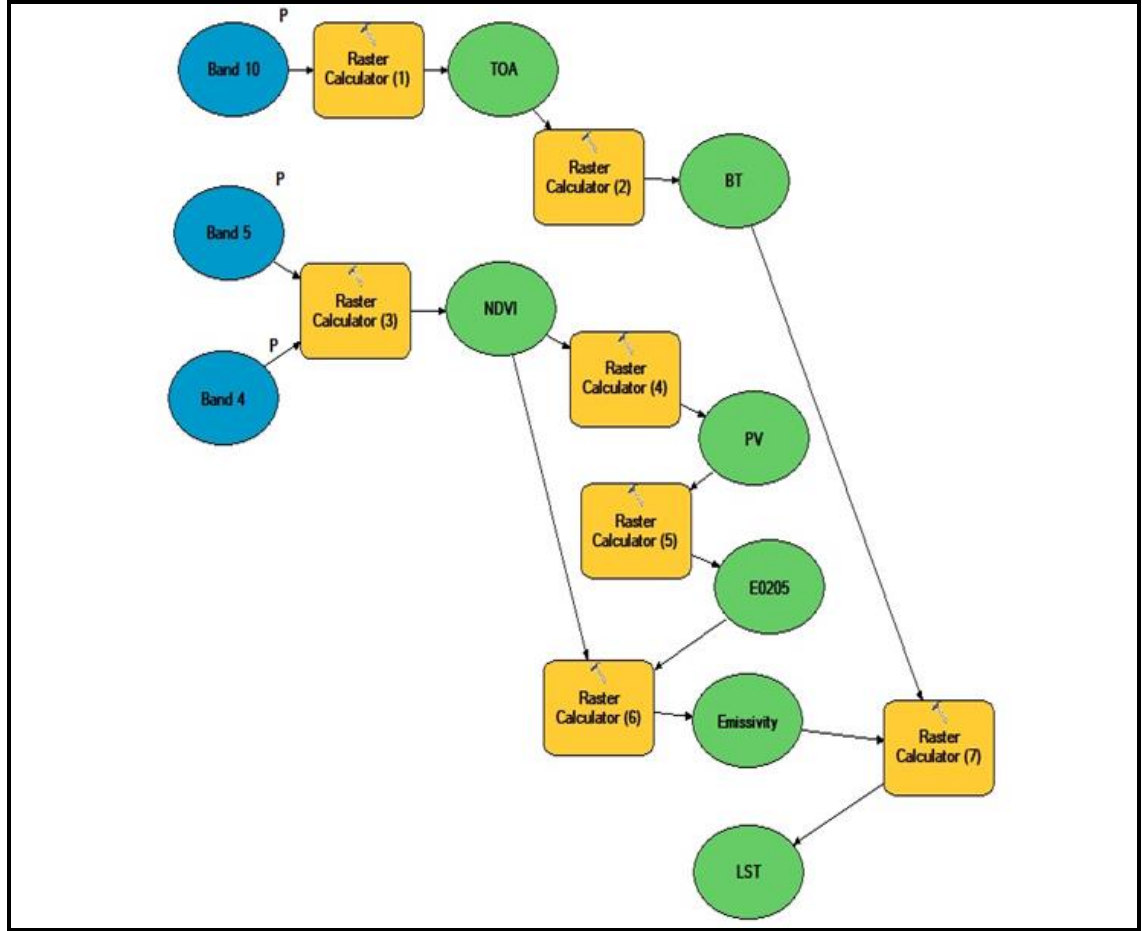

Fig. 3. Developed model using ArcGIS 10.3.1

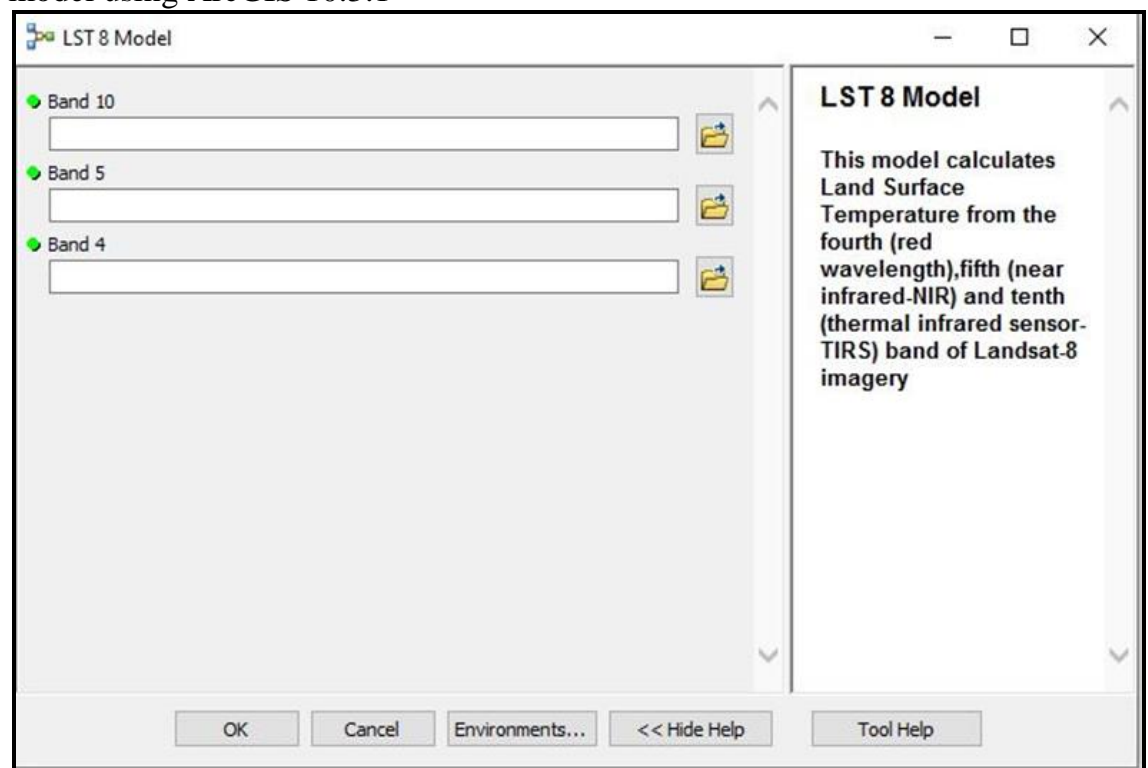

Fig. 4. Input menu of developed model using ArcGIS 10.3.1 


\section{Conclusions}

The model created in ArcGIS Desktop 10.3.1, estimated the LST for the selected datasets over the study area. The model was created using TIRS band 10 and visible and near infrared bands of LANDSAT 8. Brightness temperature is calculating using Band 10 and NDVI, emissivity of different land cover types, derived from Band 5 and Band 4 of LANDSAT 8. When user inputs required bands (4,5 and 10) of Landsat- 8 data in input menu then the model calculate automatically LST and display output. LST is an important parameter for thermal studies therefore many researchers to get to the LST values easy and they can apply them in a number of researches and project works. The model presented in this paper produced quite good results and can be considered satisfactorily.

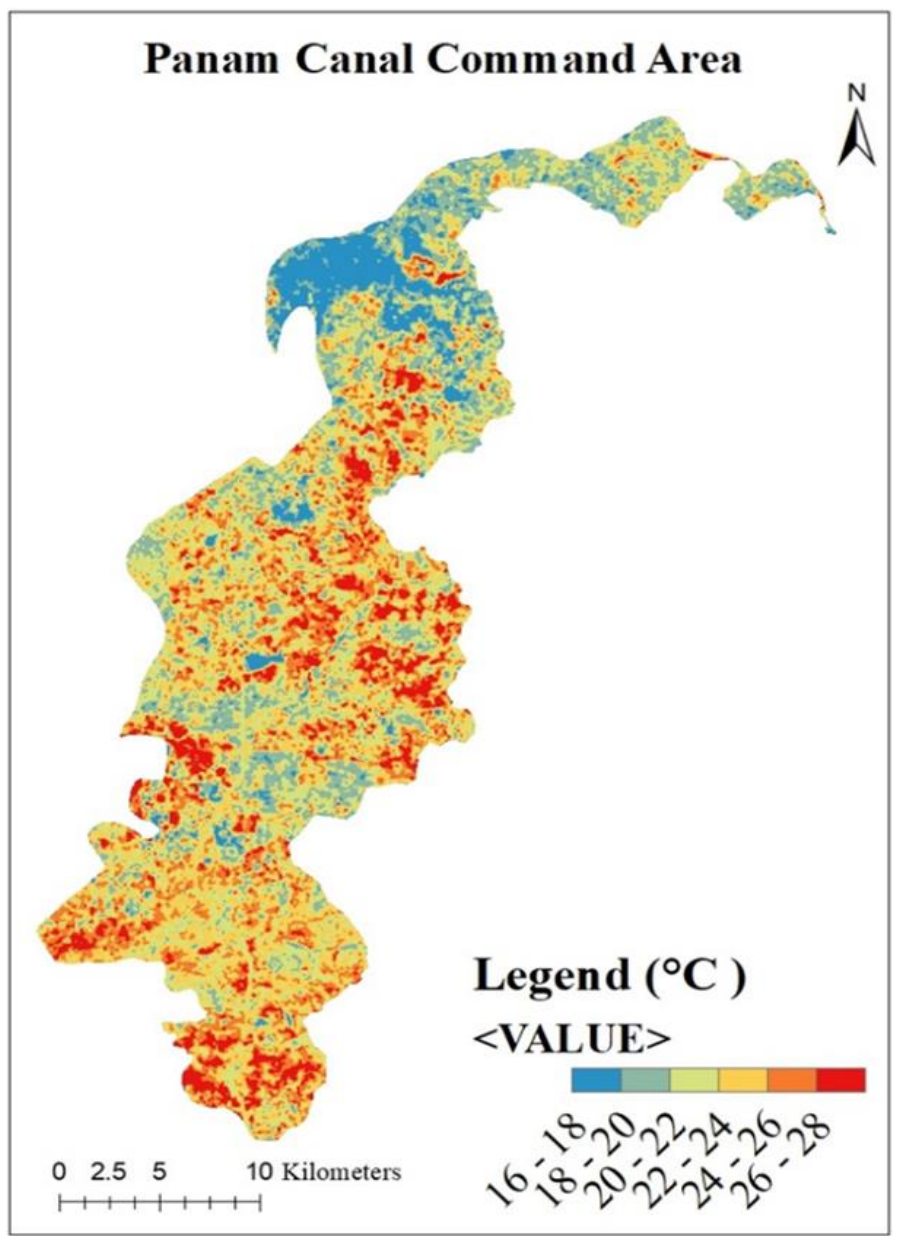

Fig. 5. LST acquired on 23 - JAN-20 (path/row: 148/44)

\section{References}

Avdan, U., Jovanovska, G. (2016). Algorithm for Automated Mapping of Land Surface Temperature Using LANDSAT 8 Satellite Data. 2016.

Çelik, B., Kaya, Ş., Alganci, U., Seker, DZ. (2019). Assessment of the relationship between land use/cover changes and land surface temperatures: a case study of thermal remote sensing, FEB Fresenius Environ. Bull.,3, 541

Department of the Interior U.S. Geological Survey. (2016). Landsat 8 Data Users Handbook. Nasa, 8(June),97.

Guillevic, P., Göttsche, F., Nickeson, J., Hulley, G., Ghent, D., Yu, Y., ... Camacho, F. (2018). Land surface temperature product validation best practice protocol version 1.1. Best Practice for SatelliteDerived Land Product Validation (p. 60): Land Product Validation Subgroup (WGCV/CEOS),
doi(January), 58. doi.10.5067/doc/ceoswgcv/ lpv/lst.001

Ibrahim, M., Abu-mallouh, H. (2018). Estimate Land Surface Temperature in Relation to Land Use Types and Geological Formations Using Spectral Remote Sensing Data in Northeast Jordan. 2018, 174-185. https://doi.org/10.4236/ojg.2018.82011

Kaya, Ş., Çelik, B., Gazioğlu, C., Algancı, U. Şeker, DZ. (2017). Assessment of the Relationship between Land Cover and Land Surface Temperatures Utilizing Remotely Sensed Data: A Case Study of Silivri, 19th MESAEP Symposium on Environmental and Health Inequity, Rome, ITALY, 3-6 Dec 2017.

Kaya, S., Gazioğlu, C., Sertel, E., Şeker, D.Z., Algancı, U., (2015). Rapid determination of land use/cover changes using data fusion. The 36th Asian Conference on Remote Sensing "Fostering Resilient Growth in Asia", Metro Manila, Filipinler, 19-23 October 2015. 
Jeevalakshmi, D., Narayana Reddy, S., Manikiam, B. (2017). Land surface temperature retrieval from LANDSAT data using emissivity estimation. International Journal of Applied Engineering Research, 12(20), 9679-9687.

Oğuz, H. (2017). Automated Land Surface Temperature Retrieval From Landsat 8 Satellite Imagery: a Case Study of Diyarbakir - Turkey. Turkish Journal of Forest Science, 1(1), 33-43. doi.10.32328/ turkjforsci.296845

Orhan, O., Yakar, M. (2016). Investigating land surface temperature changes using Landsat data in Konya, Turkey. International Archives of the Photogrammetry, Remote Sensing and Spatial Information Sciences - ISPRS Archives, 41(July), 285-289. doi.10.5194/isprsarchives-XLI-B8-2852016

Sun, Y. (2008). Retrieval and Application of Land Surface Temperature. Geo.Utexas.Edu, 1(1), 1-27.

Zaharaddeen, I., Ibrahim, B., Zachariah, A. (2016). Estimation of land surface temperature of kaduna metropolis, nigeria using landsat images. Journal of Chemical and Pharmaceutical Sciences, 11(3), 3642. 